\title{
Eutanásia em paciente terminal: concepções de médicos e enfermeiros intensivistas ${ }^{*}$
}

Recebido em: 09/07/2010

Este trabalho teve como objetivo investigar percepções de enfermeiros e médicos intensivistas no tocante à prática da eutanásia em pacientes terminais. Esta pesquisa qualitativa foi realizada entre novembro e dezembro de 2009 em duas unidades de terapia intensiva no município de Campina Grande, Paraíba. Foram entrevistados três médicos e dez enfermeiras. Os resultados apontaram as categóricas concepções acerca da eutanásia e o posicionamento em relação à prática da eutanásia. Os enfermeiros e médicos intensivistas reconhecem os sentimentos vivenciados pelos pacientes irreversíveis. Consideramos que a eutanásia ainda é um tema bastante polêmico e carece de discussões maiores, principalmente em se tratando de pacientes em estado terminal.

Descritores: Eutanásia, Paciente Terminal, Enfermagem, Bioética.

\section{Euthanasia in terminal patients: views of intensive care physicians and nurses}

This study aimed to investigate perceptions of nurses and intensive care physicians regarding the practice of euthanasia in terminal patients. This study was carried out between November and December 2009 in two intensive care units in Campina Grande, Paraíba. It was interviewed three doctors and ten nurses. The results showed categorical conceptions of euthanasia and practices to euthanasia. The nurses and intensive care physicians recognize the feelings experienced by patients irreversible. We believe that euthanasia is still a very controversial issue and requires more discussions, especially when dealing with terminally ill patients.

Descriptors: Euthanasia, Terminal Patient, Nursing, Bioethics.

\section{La eutanasia en pacientes terminales: opiniones de médicos y enfermeras intensivistas}

Este estudio tuvo como objetivo investigar las percepciones de las enfermeras y los médicos intensivistas en relación con la práctica de la eutanasia en pacientes terminales. Esta investigación cualitativa se realizó entre noviembre y diciembre de 2009 en dos unidades de cuidados intensivos en Campina Grande, Paraíba. Se entrevisto tres médicos y diez enfermeras. Los resultados indicaron concepciones categóricas sobre la eutanasia y el posicionamiento en relación a la práctica de la eutanasia. Las enfermeras y los médicos de cuidados intensivos reconocen los sentimientos experimentados por los pacientes irreversibles. Creemos que la eutanasia sigue siendo un tema muy controvertido y requiere de más discusiones, sobre todo cuando se trata de pacientes con enfermedades terminales.

Descriptores: Eutanasia, Paciente Terminal, Enfermería, Bioética.

\section{INTRODUÇÃO}

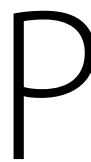

ara falar de vida e morte, é necessário fazer algumas abordagens sobre o significado de vida e morte. O surgimento da vida é afirmado por alguns a partir da fecundação; outros acreditam que a nidação (fixação do ovo no útero) e a cerebralização (formação do córtex cerebral) são o momento em que a vida se inicia; já alguns se firmam na tese de que não há um momento exato, seria uma construção, ou seja, um processo; ainda há aqueles que compreendem a aceitação do indivíduo na sociedade como o ponto inicial da vida. Com relação ao profissional de enfermagem, a teoria defendida é a concepcionista, que respeita a vida desde a fecundação até a morte ${ }^{(1)}$.

O momento de estabelecer a presença da morte é discutível por várias correntes. É mais difícil do que defini-la, pois, assim como a vida, não possui definitivas conclusões a respeito. Anteriormente, a morte era definida quando ocorria a parada cardíaca, mas, com

1 Enfermeira, Graduada pela Faculdade de Ciências Médicas de Campina Grande, PB.

2 Enfermeira, Mestranda pelo Programa de Pós-Graduação pela Universidade Federal da Paraíba - UFPB. Integrante do Grupo de Pesquisa em Saúde da Mulher - Gepsam.

Docente da Faculdade de Ciências Médicas de Campina Grande, PB.

3 Enfermeira, Doutoranda pelo Programa de Ciências e Tecnologia da UFCG. Coordenadora do Comitê de Ética do Cesed. Docente do Curso de Enfermagem

da Faculdade de Ciências Médicas de Campina Grande, PB.

4 Acadêmica de Enfermagem da Faculdade de Ciências Médicas de Campina Grande, PB.

5 Acadêmica de Enfermagem da Faculdade de Ciências Médicas de Campina Grande, PB.

* Parte integrante da monografia intitulada Percepções de Enfermeiros e Médicos Atuantes na Unidade de Terapia Intensiva sobre Eutanásia e Paciente Terminal. 
os transplantes cardíacos, houve uma mudança na norma de estabelecimento da morte, e essa passou a ser definida a partir da cessação da atividade cerebral ${ }^{(1)}$.

Alguns significados quanto à prática que põe fim à vida são analisados durante o passar do tempo até os dias atuais. A eutanásia adquire um significado de pôr fim à vida de pessoas que estejam com enfermidade, sem que haja para elas condições de exercer a vida de forma humana; não se tratam de pessoas sadias, mas que se encontram em uma situação de deficiência no que diz respeito à saúde e, consequentemente, à vida, uma vez que essas estão interligadas ${ }^{(2)}$.

A eutanásia pode ocorrer por dois meios: de forma voluntária, quando é exercida pelo próprio paciente ou a pedido do mesmo; ou involuntariamente, que acontece sem o consentimento do paciente, ou seja, alguém que decide o momento final da vida do indivíduo(3).

A eutanásia trata da morte, independentemente da forma como ela irá ocorrer. De acordo com a lei brasileira, essa prática é considerada crime e obviamente estará sujeito à punição aquele que for responsável por esse ato ${ }^{(2)}$.

A aceitação da morte, em sua maioria, é bastante conturbada, mas não para todos, pois há aqueles, frente a um caso irreversível, que acreditam que o tratamento acarretará maior sofrimento para o paciente, além do gasto inútil com investimento "desnecessário", já que não há esperança para o mesmo ${ }^{(3)}$.

O paciente terminal apresenta uma probabilidade alta de morrer em um tempo relativamente curto, de acordo com uma condição de irreversibilidade. Porém, percebese que o profissional de saúde encara certo grau de dificuldade para admitir que não há mais "nada" para fazer pelo paciente. Sendo assim, é comum que tal profissional lute para manter o paciente vivo, colocando-o em uma situação de desnecessário

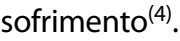

Neste estudo, não se tem a pretensão de emitir algum tipo de juízo de valor sobre a eutanásia, mas apresentar, por meio das leituras realizadas, reflexões diversas sobre essa temática. Além do mais, como um meio de obter dados mais significativos, realizar uma investigação que permita detectar as representações dos profissionais de saúde no que diz respeito à eutanásia.

Algumas pessoas desconhecem a essência da prática da eutanásia, adquirindo, portanto, um conceito insatisfatório ao proposto pela temática. É preciso conhecer os aspectos positivos e negativos para então formar uma opinião. Sendo assim, alguns profissionais que trabalham em unidades de terapia intensiva têm visões diversas sobre o tema, levando a questionamentos a favor e contra essa prática.

Nos últimos anos, foi possível observar algumas reportagens bastante polêmicas envolvendo a eutanásia, ora decorrente de fatos divulgados na imprensa internacional, ora de eventos nacionais.

Como aspecto mais relevante, que norteou o interesse em abordar o tema em questão, houve o reconhecimento da importância de desenvolver um estudo mais aprofundado e provido de análise de dados que, além da contribuição dentro dos conhecimentos da ética, proporcione um grande valor social.

Justifica-se também pela necessidade de conhecer a opinião de profissionais que atuam na unidade de terapia intensiva sobre a eutanásia em paciente terminal. Os resultados serão fornecidos à instituição, assim como ficarão disponíveis para os participantes, de modo que possam fazer uma análise situacional do ambiente de trabalho e deles próprios.

Portanto, este trabalho teve como principal intenção investigar as percepções dos profissionais de saúde, mais precisamente enfermeiros e médicos intensivistas, no tocante à prática da eutanásia em pacientes terminais, e como objetivos específicos identificar as principais percepções dos profissionais de saúde diante da eutanásia em pacientes terminais e identificar até que ponto a ética e a religião influenciam na decisão da equipe de saúde de apoiar ou não a eutanásia.

\section{METODOLOGIA}

Pesquisa exploratória, descritiva, com abordagem qualitativa. Esse tipo de abordagem favorece um relacionamento com maior permanência e flexibilidade entre o pesquisador e os entrevistados, que lidam com informações mais subjetivas, de abordagens mais amplas e com maior riqueza de detalhes ${ }^{(5)}$.

O estudo foi realizado entre novembro e dezembro de 2009 em Unidades de Terapia Intensiva (UTI) de dois hospitais no município de Campina Grande, sendo um público e outro privado. Campina Grande localiza-se no interior do estado da Paraíba, no agreste, na parte oriental do Planalto da Borborema, e possui 379.871 habitantes.

A população foi constituída de médicos e enfermeiros atuantes nas UTIs dos dois hospitais mencionados. A amostra foi do tipo não probabilística, por acessibilidade, composta de dez enfermeiros e três médicos que desejaram participar voluntariamente.

Também foi utilizada a entrevista semiestruturada, que permite uma cobertura mais profunda sobre determinados assuntos, além de apoiar claramente a sequência das questões e, assim, facilitar a abordagem utilizada(6). Essas permitem maior flexibilidade e uma relação maior entre pesquisador e entrevistado. $O$ nome dos participantes foi resguardado, tendo em vista as questões éticas que envolvem pesquisas com seres humanos.

Os dados qualitativos foram analisados através da Análise de Conteúdo do tipo Categorial Temática proposta por Bardin ${ }^{(7)}$, pois essa é uma técnica de investigação que parte de uma descrição objetiva e sistemática do conteúdo das comunicações, tendo uma organização própria no procedimento da análise, que permite a inferência de conhecimentos referente às condições de produção/recepção dessas mensagens.

Alguns passos foram seguidos para nortear a análise desse estudo, os quais descreveremos a seguir:

1 - contato com as entrevistas, realizando leituras flutuantes e 
posteriormente composição do corpus correspondendo a 13 entrevistas;

2 - separação do material em temas e depois em categorias e subcategorias;

3 - tratamento e análise dos dados;

4 - considerações éticas da pesquisa.

Durante o desenvolvimento da pesquisa, adotamos os princípios éticos dispostos na resolução $n^{\circ} 196 / 96$ do Conselho Nacional de Saúde ${ }^{(8)}$, permitindo que os colaboradores ficassem esclarecidos e livres para participarem da pesquisa, estando cientes de nosso objetivo e do direito de interromper sua participação no momento que lhes conviesse. Além do mais, seguiram-se as observâncias que se referem à autonomia/liberdade de os enfermeiros e médicos participarem ou não do estudo.

Também, zelamos de forma ética ao que se refere à garantia da privacidade, do sigilo e do anonimato dos colaboradores ${ }^{(8)}$.

No que tange à pesquisa qualitativa, o anonimato e a privacidade dos depoimentos prestados foram garantidos utilizando a sigla "E" seguida de números para designar cada informante. Após serem informados sobre todas as etapas, os objetivos, as finalidades e as formas de divulgação dos resultados e concordarem em participar da pesquisa, os mesmos assinaram o Termo de Consentimento Livre e Esclarecido.

\section{RESULTADOS E DISCUSSÃO}

Participaram da pesquisa 13 profissionais, sendo dez enfermeiros, equivalendo a $77 \%$ dos participantes, e três médicos, ou seja, $23 \%$ dos participantes, que exercem suas atividades nas UTIs de dois hospitais, um público e outro privado, do município de Campina Grande, PB.

A pouca quantidade de profissionais da área de medicina ocorreu devido a uma resistência por parte dos mesmos na realização da pesquisa, que, em sua maioria, se opuseram a responder a entrevista, com alegações das mais diversas; sendo respeitadas as observâncias éticas,não insistimos na realização das entrevistas.

A eutanásia possui termos semelhantes, conhecidos como ortotanásia e distanásia, que são definidos da seguinte forma: ortotanásia possui o sentido de morte em seu tempo, sem presença de abreviação ou prolongamentos desproporcionais do processo de morrer. Diferentemente da eutanásia, a ortotanásia é sensível ao alívio das dores e ao processo de humanização, não incorre em prolongamentos abusivos com a aplicação de meios desnecessários que acarretariam sofrimentos adicionais ${ }^{(9)}$.

Já a distanásia é conceituada da seguinte forma: "Morte lenta, ansiosa e com muito sofrimento". Significa, portanto, prolongamento exagerado da morte de um paciente, podendo tal termo ser também empregado como sinônimo de tratamento inútil; trata-se portanto, de atitude médica que, com o objetivo de salvar a vida do paciente terminal, submete-o a grande sofrimento ${ }^{(9)}$. Em tal conduta, não se prolonga a vida propriamente dita, mas o processo de morrer. Quando questionados em relação à "concepção sobre eutanásia", diferentes ideias foram expostas, permitindo a elaboração da seguinte categoria:

\section{Categoria I - diferentes concepções acerca da eutanásia}

Percebeu-se que alguns profissionais compreenderam parcialmente o conceito de eutanásia, uma vez que foi elaborado de forma incompleta, como evidenciado a seguir:

"Processo de adiamento da morte em pacientes considerados terminais". (E4)

A eutanásia trata-se de um ato intencional, mesmo que utilizada para o "bem", na tentativa de alívio do sofrimento, trata-se de crime, uma vez que a Constituição Brasileira assegura o direito à vida ${ }^{(10)}$. Pode ocorrer por piedade ou antecipação da morte do doente irreversível ou terminal, ante a incurabilidade de sua patologia, insuportabilidade de seu sofrimento e inutilidade de seu tratamento ${ }^{(11)}$, e não somente no paciente terminal, como referiu o entrevistado 4. Após o trauma, 20\% dos acidentados permanecem em UTI durante dias, semanas ou até meses ${ }^{(12)}$ Alguns desses traumas acarretam estado vegetativo ao paciente. Logo, a eutanásia pode ser efetuada em pessoas que se encontram na situação supracitada e não apenas em pacientes terminais.

Foi observada ainda a compreensão parcial do conceito de eutanásia dos profissionais entrevistados, uma vez que foi conceituado de forma incompleta, como segue:

"Seria a interrupção de uma vida, sem a autorização da pessoa (geralmente apontada por familiares ou terceiros), motivada pela falta de expectativa diante de um diagnóstico ou pelo quadro clínico irreversível da pessoa". (E10)

O discurso faz alusão somente à eutanásia passiva. A eutanásia pode ocorrer por dois meios: de forma voluntária, realizada pelo próprio paciente ou a pedido do mesmo, ou de forma involuntária, quando é realizada por outrem com ou sem o consentimento do paciente ${ }^{(13)}$. Já outros autores definem a eutanásia voluntária como "ativa" e a involuntária como "passiva". Quanto ao tipo de ação, a eutanásia ativa é a que se caracteriza pelo ato de provocar a morte por fins misericordiosos, sem sofrimento do paciente, e a eutanásia passiva trata-se da não-iniciação de uma ação médica ou interrupção de uma medida extraordinária, objetivando diminuir o sofrimento, seguida de morte do paciente. Quanto ao consentimento do paciente, temos a eutanásia voluntária, que ocorre quando a morte atende à vontade do paciente, e eutanásia involuntária, quando é realizada sem o consentimento do paciente. Embora se diferenciem, ambas se tratam de morte do paciente ${ }^{(14)}$.

Ainda é observado como o emprego ou abstenção de procedimentos que viabilizem antecipar ou provocar o óbito de um paciente com quadro irreversível na tentativa de livrá-lo dos intensos sofrimentos que o acometem ${ }^{(15)}$.

O termo eutanásia é originado do grego, com significado de boa morte ou morte digna. Segundo os mesmos autores, foi usado pela primeira vez pelo historiador latino Suetônio, ao descrever a morte "suave"(13).

Verificou-se que alguns profissionais compreenderam o conceito de eutanásia como se vê a seguir:

"Éa prática de abreviar a vida de um paciente incurável, vegetativo, ou seja, sem chances de uma sobrevivência normal'. (E5)

O indivíduo que sofrerá a eutanásia se encontra em inutilidade como ser humano, ou seja, não se trata de pessoa sadia, mas fora dos "padrões" de uma sobrevida normal ${ }^{(14)}$. 
Em seguida, foi questionado quem era a favor ou contra a eutanásia, e verificou-se que entre os profissionais entrevistados apenas um se posicionou em concordância com a prática da eutanásia, alegando acreditar que para "tudo" existem exceções, ou seja, dependendo da situação do indivíduo a eutanásia seria a melhor opção. Dessa forma, e a partir da questão norteadora, elaborou-se a seguinte categoria:

\section{Categoria II - posicionamento em relação à eutanásia}

Todos os profissionais entrevistados discordaram da eutanásia, podendo estar associado ao fato de ser considerada crime pela lei brasileira, a sua prática, uma vez que tal lei assegura o direito à vida ${ }^{(10)}$.

Constitui-se crime a utilização de medicamentos em doses letais ou a simples omissão dos cuidados necessários ao paciente, ambos com a finalidade de causar a morte ${ }^{(17)}$. Não se pode negar ao paciente incurável os devidos cuidados médicos vitais, sem os quais ele morreria, nem deixar cuidados ordinários disponíveis, ainda que sejam parcialmente ineficazes, nem renunciar tratamento ao doente, mesmo se não houver possibilidade de recuperação para o mesmo ${ }^{(11)}$. Diante dos discursos, foi possível dividi-los e subcategorizá-los para melhor esclarecimento:

\section{Subcategoria I: em favor da vida}

No próximo discurso, percebemos que um dos participantes afirma não ser a favor em defesa do direito de viver.

"Não concordo porque estudei e pratico medicina para salvar vidas e a defendo em todas as circunstâncias". (E1)

O estudante de medicina é moldado desde cedo para encarar a morte como "o maior dos adversários", devendo sempre combatê-lo e, se possível, vencê-lo graças à melhor ciência, ou competência, disponível(13). O direito à vida deverá prevalecer sobre qualquer outro direito, pois o homem não possui o direito de matar-se, nem tampouco de exigir que outrem o mate, já que o mesmo não é dono da própria vida ${ }^{(11)}$.

\section{Subcategoria II: por questões religiosas}

A Igreja sempre teve uma forte influência no que diz respeito à ética. A religião sempre tem sido a maior fonte de moralidade. As pessoas apegam-se na fé em Deus, juntamente com as doutrinas religiosas, que seriam as normas éticas da Igreja, e de certo modo são bem influenciadas em suas práticas ${ }^{(3)}$.

No que se refere a questões religiosas, alguns profissionais discordam da eutanásia, como segue:

"Não devemos questionar a vida, a morte ou o sofrimento. Talvez aquele período de sofrimento seja a única oportunidade de a pessoa alcançar o arrependimento e conciliar-se com Deus. Quando adiantamos a morte, talvez estejamos roubando essa oportunidade!". (E4)

"Porque enquanto há vida há esperança, e mesmo nos casos da falta da mesma, o 'homem' não tem o direito de decidir quando a vida de alguém deve chegar ao fim, só Deus tem esse direito". (E5) "Crenças religiosas". (E10)

É percebido nos discursos que as crenças religiosas constituem forte influência na "não-aceitação" da prática da eutanásia. Sendo a maioria dos brasileiros cristã, podemos relacionar a religião à não-aceitação da eutanásia. O cristianismo é contrário à eutanásia. $O$ judaísmo adota uma atitude de marginalização aos leprosos, todavia nunca analisa qualquer tipo de possibilidade de retirada da vida miserável(2). 0 judaísmo distingue entre o prolongamento da vida do paciente, que é obrigatório, e o prolongamento da agonia, que não é obrigatório. Por conseguinte, havendo convicção médica de que o paciente agoniza, com possibilidade de falecimento dentro de três dias, então se admite a suspensão das tentativas de reanimação e a interrupção de tratamento não analgésico ${ }^{(11)}$.

Thomas Morus, considerado um santo da Igreja católica, é a favor da eutanásia ao afirmar que, se a vida não passa de um insuportável tormento, melhor então que se ponha fim a mesma. Ele apenas aconselha a morte ao doente, portanto não a impõe ${ }^{(2)}$.

\section{"Todos os profissionais entrevistados \\ Subcategoria III: não concorda por questões éticas} discordaram da eutanásia, podendo estar associado ao fato de ser considerada crime pela lei brasileira"
A ética serve como um manual das condutas humanas, pois através dela que é possível discernir o correto do errado, ou o justo do injusto, o que se deve e o que se pode fazer e o que não se deve e do que não se pode fazer. É necessária a existência das leis para pelo menos controlar e restringir os atos ${ }^{(3)}$, porque a natureza humana é egoísta e possui uma tendência

de usar métodos e atos violentos, a fim de tirar proveito dos mais fracos e indefesos. Tirar a vida de uma pessoa que está em fase terminal, por exemplo, para dar a preferência a alguém quanto a algum tipo de atendimento seria um ato ilícito em que o autor dessa prática estaria usando de artifícios para benefício próprio ou de outrem.

Há limites éticos da intervenção sobre o ser humano, desde o início da vida até o fim dela(17). Questiona-se até que ponto o ser humano poderá decidir quanto a própria vida, escolhendo o momento exato de extingui-la. Há quem defenda que não cabe à ciência dar a resposta a essas questões éticas existenciais, porém a ela compete apenas oferecer subsídios para que cada pessoa dê a própria resposta aos dilemas éticos, através de reflexões éticas. Concordando com essa assertiva estão os discursos alocados a seguir:

"Nunca concordaria por questões ético-religiosas; é ferir muito a ética profissional. Eu não estou aqui para tentar salvar a vida? Como é que eu vou pensar em tirá-la?". (E7)

"Não concordo porque a ética tem que estar acima de tudo nas questões de vida e morte". (E11)

A consciência por vezes auxilia nos atos a serem realizados. Essa consciência se refere à voz interior que, antes de agir, a pessoa tenta pensar e analisar ${ }^{(2)}$. Obviamente essa consciência referida se trata de uma consciência "acertada", pois, se for errônea, então 
não servirá como boa direção em uma conduta.

A bioética está vinculada a três princípios: autonomia, beneficência e justiça. A autonomia se refere ao respeito à vontade e ao direito que o paciente tem de se governar, favorecendo assim que a pessoa possa ter participação ativa dos cuidados referentes a sua vida. Uma vez infringido esse primeiro princípio, consequentemente os demais serão afetados, pois um indivíduo que tem por vontade continuar a viver, por exemplo, mesmo sem expectativas por parte da equipe de saúde, a ele é dado o direito de continuar o tratamento. E se possivelmente alguém violar tal lei, estará ferindo os demais princípios, como comentado anteriormente ${ }^{(18)}$.

\section{CONSIDERAÇÕES FINAIS}

A partir dos questionamentos deste estudo, foi possível identificar as percepções dos profissionais de saúde, mais precisamente enfermeiros e médicos intensivistas, no tocante à prática da eutanásia em pacientes terminais. Observou-se que:

- alguns profissionais compreendem parcialmente o conceito de eutanásia, outros compreendem totalmente o conceito;

- houve unanimidade entre os profissionais que discordaram da prática da eutanásia, uma vez que é considerada crime de acordo com a lei brasileira. E os principais motivos foram sobretudo por questões religiosas e éticas. Identificou-se a influência das questões éticas e religiosas na tomada de decisão da equipe de saúde de apoiar ou não a eutanásia além da valorização da vida.

Evidencia-se, portanto, com este trabalho, que os profissionais da equipe de saúde, mais precisamente enfermeiros e médicos, reconhecem os sentimentos atrozes vivenciados pelos pacientes irreversíveis, porém não optam por meios como as práticas da eutanásia, voltadas à minimização de tais sofrimentos, uma vez que infringiria principalmente os aspectos jurídicos, religiosos e éticos que lhes são impostos.

Enfim, a eutanásia existe, assim como sua prática, mas, por não ser aceita pelas leis de nosso país, tem dificultado o direito à morte de muitos brasileiros que clamam para que seus sofrimentos sejam cessados. Tal lei poderia ser revista por parte das autoridades e pensá-la em casos de pacientes terminais, por exemplo, cujo quadro é irreversível e a continuação do tratamento só lhes acarretará sofrimentos atrozes; no entanto, ainda é um dilema ético importante na saúde que merece maiores discussões.

Logo, mediante abordagens feitas a respeito do tema proposto pelo trabalho, assim como estudo mais aprofundado e provido de análise de dados, espera-se que, além da contribuição dentro dos conhecimentos da ética, proporcione um grande valor social.

\section{Referências}

1. Gelain I. Deontologia e enfermagem. São Paulo: EPU; 2007.

2. Pessini L, Barchifontaine CP. Problemas atuais de bioética. $7^{a}$ ed. São Paulo:

Centro Universitário São Camilo; 2005.

3. Kirchner L. Bioética: o que é? Para que serve?. São Paulo. 6a ed. Aparecida:

Editora Santuário; 2002.

4. Quintana AM. Sentimentos e percepções da equipe de saúde frente ao

paciente terminal [Internet]. [citado em 27 Jul 09].

Disponível em: HYPERLINK "http://www.revistasusp.sibi.usp.br/scielo.

php?pid=S0103-863X2006000300012\&script=sci_arttext\&tIng=pt" http://www. revistasusp.sibi.usp.br/scielo.php?pid=S0103.

5. Minayo MCS. O desafio do conhecimento - pesquisa qualitativa em saúde. $10^{a}$ ed. São Paulo: Hucitec; 2007.

6. Bernard R. Research methods in anthropology: qualitative and quantitative

approaches. Thousand Oaks: Sage; 1994.

7. Bardin L. Análise de conteúdo. Lisboa: Edições 70; 1977.

8. Conselho Nacional de Saúde (BR). Aspectos éticos da pesquisa envolvendo

seres humanos. Resolução № 196. Brasília: Conselho Nacional de Saúde; 1996.

9. Pessini L. Distanásia: até quando investir sem agredir? [Internet]. [citado em

2010 Mar 17]. Disponível em: HYPERLINK "http://www.portalmedico.org.br/

revista/bio1 v4/distanasia.html" http://www.portalmedico.org.br/revista/bio1v4/

distanasia.html.

10. Kersten I. A Constituição do Brasil e os Direitos Humanos. In: Âmbito jurídico [Internet]. [citado em 2005 Ago 31].

Disponível em: HYPERLINK "http://www.ambito-juridico.com.br/site/index. php?n_link=artigos_leitura_pdf\&artigo_id=339" http://www.ambito-juridico.

com.br/site/index.php?n_link=artigos_leitura_pdf\&artigo_id=339
11. Diniz MH. O estado atual do biodireito. São Paulo: Saraiva; 2009.

12. Siqueira ILCP, Silva SC, Conishi RM; Sistemas de Classificação de Pacientes:

Avaliação da gravidade e da carga de trabalho de enfermagem em UTI. In:

Paciente crítico: diagnóstico e tratamento. Barueri: Manole; 2006.

13. Fortes PAC. Ética e saúde: questões éticas, deontológicas e legais: autonomia e direitos do paciente: estudos de casos. São Paulo: EPU; 2005.

14. Reiriz $A B$. Cuidados paliativos, a terceira via entre eutanásia e distanásia: ortotanásia. In: Prática hospitalar [Internet]. [citado em 2009 Nov 18]. Disponível em: HYPERLINK "http://74.125.155.132/scholar?q=cache:WmwW4jmDtpgJ:schol ar.google.com/+eutan\%C3\%A1 sia+ativa+e+eutan\%C3\%A1 sia+passiva\&hl=p t-BR\&as_sdt=2000" http://74.125.155.132/scholar?q=cache:WmwW4jmDtpgJ:sc holar.google.com/+eutan\%C3\%A1 sia+ativa+e+eutan\%C3\%A1sia+passiva\&hl=p t-BR\&as_sdt=2000.

15. Lams AR. A percepção da equipe de enfermagem frente à eutanásia

[Internet]. [citado em 2009 Jun 15]. Disponível em: http://66.102.1.104/

scholar?q=cache:8k-7_kRetGAJ:scholar.google.com/+eutan\%C3\%A1sia-

+significado\&hl=pt-BR.

16. Coutinho LM. Responsabilidade ética penal e civil do médico. Brasília: Brasília Jurídica; 1997.

17. Segre M. Limites éticos da intervenção sobre o ser humano. In: Bioética. São Paulo: Pioneira Thomson; 2002.

18. Kovács MJ. Educação para a morte. In: Psicologia: ciência e profissão [Internet]. [citado em 2009 Nov 11]. Disponível em: HYPERLINK "http://scielo.bvspsi.org.br/scielo.php?pid=s1414-98932005000300012\&script=sci_arttext" http:// scielo.bvs-psi.org.br/scielo.php?pid=s1414-98932005000300012\&script=sci arttext. 